\title{
USE OF NETWORK PLANNING METHODS IN DESIGNING MODERNIZATION OF AGRI-FOOD PROCESSING ENTERPRISE TO IMPROVE ORGANIZATION OF PRODUCTION: EXAMPLE OF MEAT PROCESSING PLANT
}

\author{
Slawomir Francik, Norbert Pedryc, Tomasz Hebda, Beata Brzychczyk \\ University of Agriculture in Krakow, Poland \\ slawomir.francik@urk.edu.pl,norbert.pedryc@ur.krakow.pl, \\ tomasz.hebda@ur.krakow.pl, beata.brzychczyk@ur.krakow.pl
}

\begin{abstract}
Project management is an integral part of any investment process. Any project management process consists of three main components: planning, scheduling and controlling. Scheduling is a frequent task in the manufacturing processes. There are various methods for scheduling, of which the most popular are the Program Evaluation and Review Technique (PERT), and Critical Path Method (CPM) - developed in 1956-1958. PERT and CPM are basically time-oriented methods in the sense that they both lead to the determination of a time schedule. The most important difference between them is that originally the time estimates for the activities were assumed deterministic in CPM and probabilistic in PERT. In this paper the PERT-COST method was used to design the modernization of production processes in a meat processing plant. The PERT-COST method adds the consideration of costs to the schedule developed by the PERT procedure. The main objective in the time-cost trade-off problems has always been the reduction in the total cost. Reducing the original project duration ("crashing PERT networks") is aimed at meeting a desired deadline while incurring the lowest cost. The research method used in the work included the typical PERT procedure (identification of specific activities and milestones, determination of the proper sequence of actions, development of a network diagram, estimation of the time of each activity, determining the critical path) and cost analysis (PERT-COST) to determine how to reduce the time schedule, while minimizing the increase in the total costs. In this paper the PERT-COST method was used to design the modernization of production processes in a meat processing plant. The production processes were analysed: sausages, pork meats, smoked meats and block products. Then, for each of the production processes, network diagrams were developed and a time-cost analysis was carried out. An optimal plan to shorten the duration of individual production processes was developed.
\end{abstract}

Keywords: network planning method, PERT-COST, time-cost trade-off problem, time schedule.

\section{Introduction}

Project management is an integral part of any investment process. In a highly competitive business environment, efficient project management becomes increasingly important. Project activities must be scheduled taking into account available resources, such as workforce, equipment and materials. Any project management process consists of three main components: planning, scheduling and controlling [1-4].

In a complex project management problem, network diagrams are often used to describe various activities and the relationships among the activities. The activity network is an acyclic, directed graph with a source node (the start of the activity in the project) and only one destination node (the end of the activity) $[3 ; 5]$.

Among various methods of scheduling, the Program Evaluation and Review Technique (PERT) and Critical Path Method (CPM), developed in 1956-1958, are the most popular and considered to be ones of the best tools $[2 ; 6 ; 7]$.

PERT and CPM are time-oriented methods - they both lead to the determination of a time schedule. The most important difference between them is that in case of CPM the execution times for individual activities (durations of activities) have been assumed deterministic and in case of PERT probabilistic (stochastic). Precise information about the duration of the activities is seldom available in the real world. The literature on this so-called PERT problem usually deals with the computation of certain characteristics of the minimum project makespan (earliest project completion) when the activity durations are random variables. The PERT assumes beta distributions for the individual task completion times $[1 ; 6 ; 8-12]$.

The graphical representation of the project activities and their interrelationship can be done on the basis of two main possible modes, that is the activity-on-arc (AOA) and the activity-on-node (AON). In the first case, each directed arc of the graph represents an activity. The nodes of the graph are identified as events. The precedence relationships between all of the activities are represented by the 
topology of the network. In the second case, an activity is associated with a node and the precedence relationship between two activities is represented by a directed arc. A project can be considered completed, if all its activities have been finished. The minimum time to complete all the activities in the activity network equals the length of the longest path from the source node to the destination node. This path is called the critical path $[3 ; 5]$.

The main objective in the time-cost trade-off problems (TCTP) has always been the reduction in the total cost. A typical technique is to crash project activities in order to minimize the makespan of the project (the time difference between the start and the finish of a sequence of jobs or tasks). Reducing the original project duration ("crashing PERT networks") is aimed at meeting a desired deadline with the lowest amount of cost. Consuming extra resources can shorten the duration of each individual activity. Minimization is usually carried out by the cost descent gradient search $[1 ; 9-11$; 13; 14]. The PERT-COST method adds the consideration of costs to the schedule developed by the PERT procedure.

\section{PERT-COST method}

The original version of PERT used the activity-on-arc (AOA) network, where each activity is represented by an arc (Figure 1). A node is used to separate an activity (an outgoing arc) from each of its immediate predecessors (an incoming arc). A node is represented by a circle and indicates EVENT, a point in time when one or more activities start and/or finish. The sequencing of the arcs thereby shows the precedence relationships between the activities. Sometimes it is necessary to use dummy activities in the network diagram. The dummy activity indicates only precedence relationships and does not require any time of effort $[8 ; 15]$.

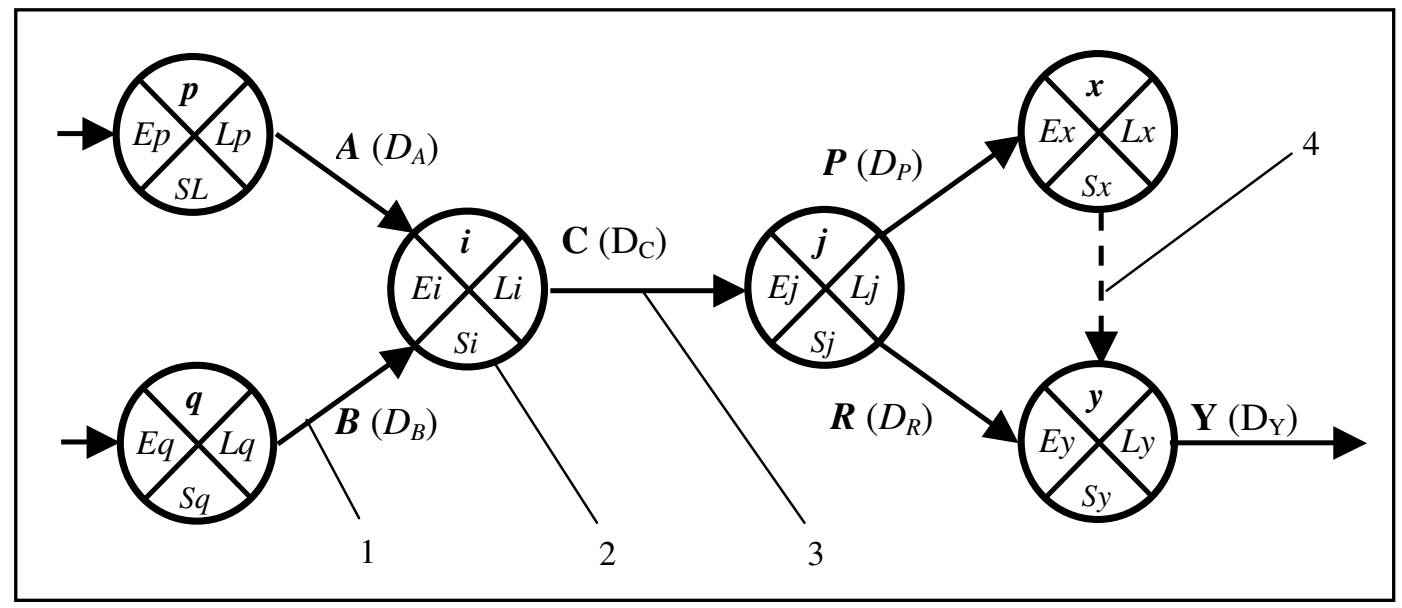

Fig. 1. Markings used in PERT network diagram: 1 - critical activity; 2 - node; 3 -activity;

4 - dummy activity; A, $B, C, P, R$ - symbolic activity assay; $D_{A}, D_{B}, D_{C}, D_{P}, D_{R}$ - durations of activities $A, B, C, P, R ; i, j, p, q, x, y$ - nodes numbers; $S i$ - slack; Ej - earliest occurrence time of event $j ; L j$ - latest occurrence time of event $j$

A path through a project network is one of the routes following the arcs from the START node to the FINISH node. The length of a path is the sum of the (estimated) durations of the activities $\left(D_{k}\right.$; $k=1, \ldots, n)$ on the path. The longest path is called the critical path.

The critical path can be identified by determining the following four parameters for each activity: $E S$ - earliest start time: the earliest time at which an activity can begin given that its predecessor activities must be completed first, $E F$ - earliest finish time, equal to the earliest start time for the activity plus the time required to complete the activity, $L F$ - latest finish time: the latest time, at which an activity can be completed without delaying the project, $L S$ - latest start time, equal to the latest finish time minus the time required to complete the activity. The critical path is the path, in which none of the activities have slack ( $L S=E S$ and $L F=E F$ for all activities in the path). To accelerate the project, it is necessary to reduce the total time required for the activities in the critical path.

Two times are calculated for each event: $E_{j}$ - earliest occurrence time of event $j, L_{j}$ - latest occurrence time of event $j$. 
The critical path calculations involve two passes: The forward pass determines the earliest occurrence times of the events, and the backward pass calculates their latest occurrence times.

Earliest Occurrence Times. The computation starts at node 1 and advance recursively to end node $n$. Set $E_{1}=0$ and calculate $E_{j}$ for every node until you reach the final node, $n$. The earliest occurrence time of event $\mathrm{i}$ is computed as (Figure 1):

$$
E i=\max \left\{E p+D_{A}, E q+D_{B}\right\},
$$

Latest Occurrence Times. Once you have computed the forward pass, the backward pass computations start at the final node $\mathrm{n}$ and end at node 1 . Set $L_{n}=E_{n}$ and calculate every node until you reach the start node, 1 . The latest occurrence time of event $\mathrm{j}$ is computed as:

$$
L j=\min \left\{L x-D_{P}, L y-D_{R}\right\},
$$

A distinguishing feature of PERT is its ability to deal with uncertainty in activity completion times. For each activity, the model includes three time estimates $[8 ; 16]$ :

- Optimistic time $(O T)$ - shortest time, in which the activity can be completed,

- Most likely time (MT) - completion time having the highest probability,

- Pessimistic time (PT) - longest time that an activity might require.

In the PERT method, the expected time (Te) for each activity is given by Equation (1):

$$
T e=\frac{O T+4 \cdot M T+P T}{6},
$$

where $O T$ - optimistic time, time units;

$M T$ - most likely time, time units;

$P T$ - pessimistic time, time units.

Under the assumption that time and cost tradeoffs for individual activities are linear, the relationship can be represented as a straight line on a graph depicting the relationship between the activity time and cost. The cost of completing the activity varies linearly between the normal time and the crash time [13; 14]. Cost per unit time for activity $\mathrm{j}$ (Slop cost) CPUTj is calculated from the equation (PERT-COST method):

$$
C P U T j=\frac{C C j-N C j}{N T j-C T j},
$$

where $N T j-$ normal time required, when activity $j$ is performed under normal conditions,

$C T j$ - crash time requiring the allocation of additional resources,

$N C j$ - normal cost, when the activity $j$ is performed in the normal time $N T j$,

$C C j$ - crash cost, when activity $j$ is completed in the crash time $C T j$.

\section{Materials and methods}

In this paper the PERT-COST method was used to design the modernization of production processes in a meat processing plant. The production processes were analysed for: sausages, pork meats, smoked meats and block products.

The research method used in the work included the typical PERT procedure (identification of specific activities and milestones, determination of the proper sequence of actions, development of a network diagram, estimating the time of each activity, determining the critical path) and cost analysis (PERT-COST) to determine how to reduce the time schedule while minimizing the increase in the total costs.

The first stage of the work was the analysis of the production processes in the meat processing plant and the development of schemes for individual production processes. Then, for each of the production processes, network diagrams were developed and a time-cost analysis was carried out, in accordance with the PERT-COST method described above. An optimal plan to shorten the duration of the analysed production processes was developed. 


\section{Results and discussion}

In the meat processing plant, the production of pork (cutting) in post-partition elements and production of different types of meat products takes place in four separate production cycles: raw material (pork) and cutting, production of smoked meats, sausages and block products (Figure 2). These processes are interrelated.

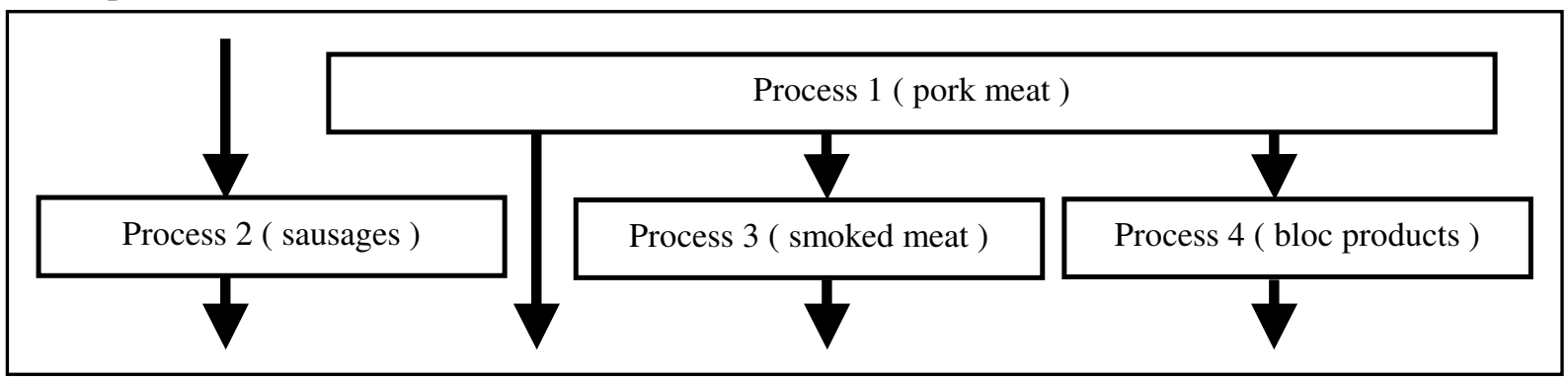

Fig. 2. Diagram of connections between production processes

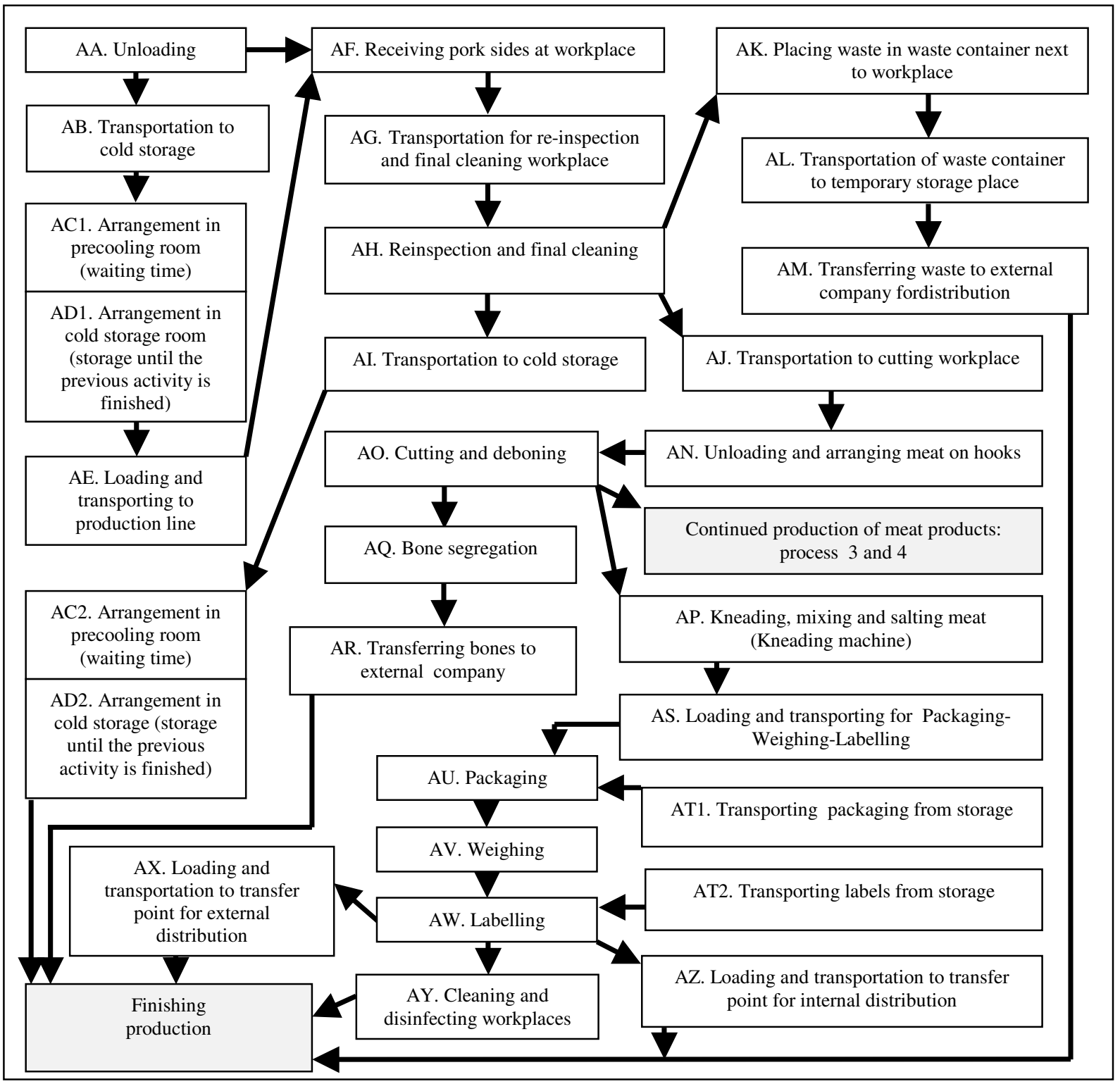

Fig. 3. Block diagram of pork meat production

For each of the production processes a diagram was prepared. As an example, the diagram for the pork meat production is presented in Fig. 3. In case of the pork meat production process, there are two 
variants. Variant one: after unloading, the meat is transferred directly to the production unit. Variant two: the meat is transported to the cold storage unit and stored there, and then transferred to the production unit.

Table 1

Activity list for pork meat production

\begin{tabular}{|c|c|c|c|c|c|}
\hline Activity & $\begin{array}{c}\text { Immediate } \\
\text { Predecessors }\end{array}$ & Activity Description & $\begin{array}{l}\text { OT, } \\
\text { min }\end{array}$ & $\begin{array}{l}\text { PT, } \\
\text { min }\end{array}$ & $\begin{array}{l}\text { MT, } \\
\text { min }\end{array}$ \\
\hline $\boldsymbol{A A}$ & - & Unloading & 25 & 45 & 40 \\
\hline$A B$ & $\boldsymbol{A A}$ & Transportation to cold storage & 15 & 35 & 20 \\
\hline$A C 1$ & $\boldsymbol{A B}$ & Arrangement in precooling room & 25 & 55 & 30 \\
\hline$A C 2$ & $A I$ & Arrangement in precooling room & 25 & 55 & 30 \\
\hline$A D 1$ & $A C 1$ & Arrangement in cold storage room & 25 & 55 & 30 \\
\hline$A D 2$ & $A C 2$ & Arrangemen in cold storage room & 25 & 55 & 30 \\
\hline $\boldsymbol{A E}$ & $\boldsymbol{A E}$ & Transportation to production line & 25 & 55 & 30 \\
\hline $\boldsymbol{A F}$ & $A A, A D 1$ & Receiving pork sides & 45 & 70 & 60 \\
\hline$A G$ & $\boldsymbol{A F}$ & $\begin{array}{c}\text { Transportation for re-inspection and final } \\
\text { cleaning }\end{array}$ & 15 & 35 & 20 \\
\hline $\boldsymbol{A H}$ & $A G$ & Re-inspection and final cleaning & 45 & 70 & 60 \\
\hline$A I$ & $\boldsymbol{A H}$ & Transportation to cold storage & 15 & 35 & 20 \\
\hline$A J$ & $A H$ & Transportation to cutting workplace & 15 & 35 & 20 \\
\hline$A K$ & $A H$ & Placing waste in waste container & 25 & 55 & 30 \\
\hline$A L$ & $A K$ & $\begin{array}{l}\text { Transportation of waste container to temporary } \\
\text { storage place }\end{array}$ & 10 & 30 & 15 \\
\hline$A M$ & $A L$ & Transferring waste to external company & 25 & 55 & 30 \\
\hline$A N$ & $A J$ & Unloading and arranging meat on hooks & 25 & 45 & 40 \\
\hline$A O$ & $A N$ & Cutting, deboning and exsanguination & 45 & 70 & 60 \\
\hline $\boldsymbol{A P}$ & AO & $\begin{array}{l}\text { Masowanie, mieszanie i solenie mięsa / } \\
\text { Kneading, mixing and salting meat }\end{array}$ & 45 & 70 & 60 \\
\hline$A Q$ & AO & Bone segregation & 25 & 55 & 30 \\
\hline$A R$ & $A Q$ & $\begin{array}{l}\text { Transferring bones to external company for } \\
\text { distribution }\end{array}$ & 25 & 55 & 30 \\
\hline$A S$ & $\boldsymbol{A P}$ & $\begin{array}{l}\text { Loading to trucks and transporting to P-W-L } \\
\text { (Packaging-Weighing-Labelling) workplaces }\end{array}$ & 15 & 35 & 20 \\
\hline$A T 1$ & - & Transporting packaging from storage & 10 & 30 & 15 \\
\hline$A U$ & $A S, A T 1$ & Packaging & 35 & 80 & 50 \\
\hline$A V$ & $A U$ & Weighing & 35 & 80 & 50 \\
\hline$A T 2$ & - & Transporting labels from storage & 10 & 30 & 15 \\
\hline$A W$ & $A V, A T 2$ & Labelling & 35 & 80 & 50 \\
\hline $\boldsymbol{A X}$ & $A W$ & $\begin{array}{c}\text { Loading and transportation to transfer point for } \\
\text { external distribution }\end{array}$ & 25 & 55 & 30 \\
\hline$A Y$ & $A W$ & Cleaning and disinfecting all workplaces & 25 & 45 & 40 \\
\hline$A Z$ & $A W$ & $\begin{array}{l}\text { Loading and transportation to transfer point for } \\
\text { internal distribution }\end{array}$ & 15 & 35 & 20 \\
\hline
\end{tabular}

Then, for each of the production processes a list of activities was developed, the sequence of activities was determined and the duration time was estimated (OT, MT and PT). The results are 
presented in the tables below. A sample set of the activities for pork meat production under the first variant is shown in Table 1.

After listing all activities for the analysed production processes, the PERT networks were created. The times were calculated for all the activities: $E S$ - the earliest start time, $E F$ - the earliest finish time, $L F$ - the latest finish time, $L S$ - the latest start time and $S L$-slack. The critical path was determined. An example of the network for the pork meat production is shown in Fig. 4.

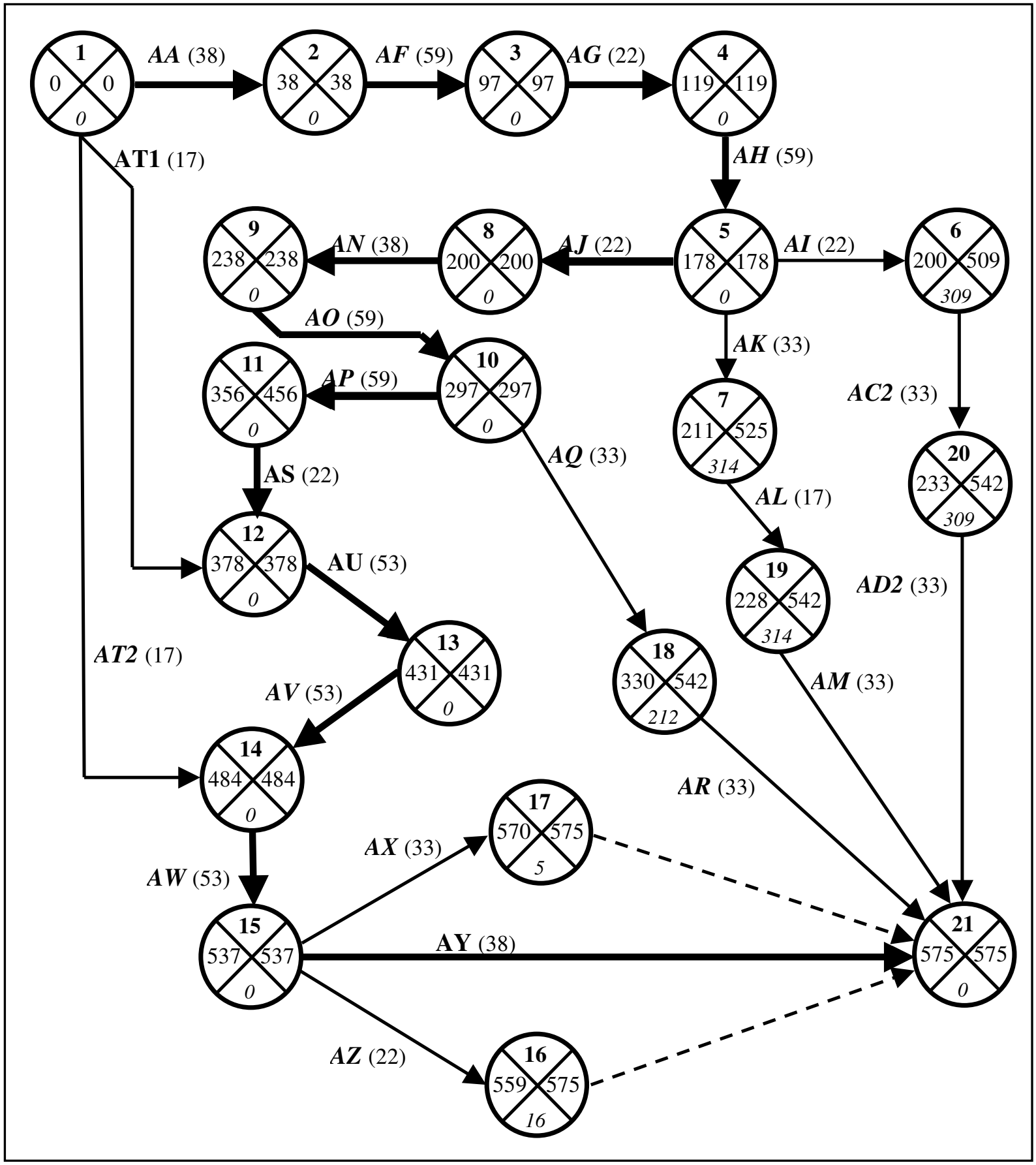

Fig. 4. Network for pork meat production

The critical path includes 13 critical activities: $A A$ (Unloading) $-A F$ (Receiving pork sides) $-A G$ (Transportation for re-inspection and final cleaning) $-H$ (Re-inspection and final cleaning) $-A J$ (Transportation to cutting workplace) - $A N$ (Unloading and arranging meat on hooks) - $A O$ (Cutting, deboning and exsanguinations) $-A P$ (Kneading, mixing and salting meat) $-A S$ Loading to trucks and transporting to $\mathrm{P}-\mathrm{W}-\mathrm{L}$ workplaces) $-A U$ (Packaging) $-A V$ (Weighing ) $-A W$ (Labelling) $-A Y$ (Cleaning and disinfecting all workplaces). The total duration of the process is 575 minutes. 
The final stage of the work was the PERT-COST time-cost analysis. The analysis showed that the time reduction for the analysed production processes is possible either through increasing the number of employees involved in the process or through an investment in machines increasing the efficiency of the processes.

Since the aim of the work was to design the modernization of the plant, the use of machines in individual production processes was analysed. The results are summarized in Table 2.

Table 2

Use of machines in the analysed production processes and the average cost gradient

\begin{tabular}{|c|c|c|c|c|c|c|c|c|c|}
\hline & \begin{tabular}{|c|} 
Process \\
1 \\
\end{tabular} & $\begin{array}{c}\text { Process } \\
2 \\
\end{array}$ & \begin{tabular}{|c|} 
Process \\
$\mathbf{3}$ \\
\end{tabular} & $\begin{array}{c}\text { Process } \\
4 \\
\end{array}$ & $\begin{array}{l}N T j, \\
\text { min }\end{array}$ & $\begin{array}{l}N C j \\
\text { PLN }\end{array}$ & $\begin{array}{l}C T j, \\
\text { min }\end{array}$ & $\begin{array}{l}C C F, \\
\text { PLN }\end{array}$ & $\begin{array}{c}\text { CPUTj, } \\
\text { PLN· } \text { min }^{-1}\end{array}$ \\
\hline Massage Tumbler & Yes & - & - & - & 59 & 10000 & 45 & 24000 & 1000 \\
\hline Meat mincer & - & Yes & - & Yes & 33 & 1500 & 25 & 3000 & 188 \\
\hline Kneader machine & - & Yes & - & Yes & 59 & 6000 & 45 & 10000 & 286 \\
\hline Stuffing machine & - & Yes & Yes & Yes & 88 & 200 & 60 & 400 & 7 \\
\hline $\begin{array}{c}\text { Packaging } \\
\text { machine }\end{array}$ & Yes & Yes & Yes & Yes & 53 & 6000 & 35 & 8000 & 111 \\
\hline $\begin{array}{l}\text { Labelling } \\
\text { machine }\end{array}$ & Yes & Yes & Yes & Yes & 53 & 4000 & 35 & 8000 & 222 \\
\hline Cutter & - & - & - & Yes & 33 & 8000 & 25 & 16000 & 1000 \\
\hline Injecting machine & - & - & Yes & Yes & 33 & 15000 & 25 & 30000 & 1875 \\
\hline
\end{tabular}

Where: Process 1 - pork meat; Process 2 - sausages; Process 3 - smoked meat; Process 4 - bloc products; $N T j$ - normal time, min; $N C j$ - normal cost, PLN; $C T j$ - crash time, min; $C C j$ - crash cost, PLN, CPUTj - cost per unit time, PLN $\cdot \mathrm{min}^{-1}$.

Two machines (a packaging machine, a labeling machine) are used in all four production processes. The cost per unit time calculated for them is $111 \mathrm{PLN} \cdot \mathrm{min}^{-1}$ and $222 \mathrm{PLN} \cdot \mathrm{min}^{-1}$, respectively. A stuffing machine is used in three production processes and the calculated cost per unit time is only $7 \mathrm{PLN} \cdot \mathrm{min}^{-1}$. Three machines (a meat mincer, a kneader machine, a injecting machine) are used in two production processes. The cost per unit time calculated for them is from $188 \mathrm{PLN} \cdot \mathrm{min}^{-1}$ to $1875 \mathrm{PLN} \cdot \mathrm{min}^{-1}$. Two machines (a massage tumbler, a cutter) are used only in one production process and the cost per time unit calculated for them is $1000 \mathrm{PLN} \cdot \mathrm{min}^{-1}$.

On the basis of the conducted PERT-COST analysis, it was stated that successive purchase of machines should be made in the order of: a packaging machine, labeling machine, stuffing machine, meat mincer, kneader machine, injecting machine, massage tumbler and a cutter.

\section{Conclusions}

1. The analysis of the individual production lines showed that modernization should include a partial replacement of the currently used machines by the machines offering higher efficiency.

2. The priority should be the purchase of the machines, which participate in all processes (a packaging machine and a labelling machine), and of the stuffing machine, as its unit cost is the lowest. In the next stage, two machines - a kneading machine and a mincing machine - should be bought.

3. The modernization project prepared with the use of the classical PERT-COST method was approved by the owner of the production facility, which confirms the applicability of the method.

\section{Acknowledgements}

This work was supported by Higher Education in Poland, statutory activities DS3600/WIPiE/2018, Faculty of Production and Power Engineering, University of Agriculture in Krakow. 


\section{References}

[1] Azaron A., Perkgoz C., Sakawa M. A genetic algorithm approach for the time-cost trade-off in PERT networks. Applied Mathematics and Computation, vol. 168, no. 2, 2005, pp. 1317-1339.

[2] Harithamahalakshmi K., Ramesh K.M., Balakuma V. etc. Construction Scheduling Using Critical Path Method And Location Based Management System. SSRG International Journal of Civil Engineering, no. April, 2017, pp. 466-471.

[3] Guerriero F., Talarico L. A solution approach to find the critical path in a time-constrained activity network. Computers and Operations Research, vol. 37, no. 9, 2010, pp. 1557-1569.

[4] Kaur P., Kumar A. Linear programming approach for solving fuzzy critical path problems with fuzzy parameters. Applied Soft Computing Journal, vol. 21, 2014, pp. 309-319.

[5] Li Z., Liu Y., Yang G. A new probability model for insuring critical path problem with heuristic algorithm. Neurocomputing, vol. 148, 2015, pp. 129-135.

[6] Conde E. A minmax regret approach to the critical path method with task interval times. European Journal of Operational Research, vol. 197, no. 1, 2009, pp. 235-242.

[7] Sadjadi S.J., Pourmoayed R., Aryanezhad M.B. A robust critical path in an environment with hybrid uncertainty. Applied Soft Computing Journal, vol. 12, no. 3, 2012, pp. 1087-1100.

[8] Mahto D. Network Techniques (PERT \& CPM). In: Essentials of Operations Research, 2014, pp. 1-48.

[9] Hashemin S.S., Fatemi Ghomi S.M.T., Modarres M. Optimal constrained non-renewable resource allocation in PERT networks with discrete activity times. Scientia Iranica, vol. 19, no. 3, 2012, pp. 841-848.

[10] Yakhchali S.H. A path enumeration approach for the analysis of critical activities in fuzzy networks. Information Sciences, vol. 204, 2012, pp. 23-35.

[11] Yakhchali S.H., S. H. Ghodsypour S.H. On the latest starting times and criticality of activities in a network with imprecise durations. Applied Mathematical Modelling, vol. 34, no. 8, 2010, pp. 2044-2058.

[12] Creemers S., Leus R., Lambrecht M. Scheduling Markovian PERT networks to maximize the net present value. Operations Research Letters, vol. 38, 2010, pp. 51-56.

[13] Nikoomaram H., Lotfi F.H., Jassbi J. etc. A New Mathematical Model for Time Cost Trade-off Problem with Budget Limitation Based on Time Value of Money. Applied Mathematical Sciences, vol. 4, no. 63, 2010, pp. 3107-3119.

[14] Kim J.Y., Kang C.W., Hwang I.K. A practical approach to project scheduling: Considering the potential quality loss cost in the time-cost tradeoff problem. International Journal of Project Management, vol. 30, no. 2, 2012, pp. 264-272.

[15] Lieberman G.J., Hillier F.S. Introduction to Operations Research. 7th Edition,.McGraw Hill, Boston, MA, 2001.

[16]El-Kholy A.M. Time-cost tradeoff analysis considering funding variability and time uncertainty. Alexandria Engineering Journal, vol. 52, no. 1, 2013, pp. 113-121. 